\title{
Long-Term Field Performance of Pervious Concrete Pavement
}

\author{
Aleksandra Radlińska, Andrea Welker, Kathryn Greising, \\ Blake Campbell, and David Littlewood \\ Department of Civil and Environmental Engineering, Villanova University, 800 Lancaster Avenue, Villanova, PA 19085, USA \\ Correspondence should be addressed to Aleksandra Radlińska, aleksandra.radlinska@villanova.edu
}

Received 12 October 2011; Revised 16 February 2012; Accepted 18 February 2012

Academic Editor: Serji N. Amirkhanian

Copyright (C 2012 Aleksandra Radlińska et al. This is an open access article distributed under the Creative Commons Attribution License, which permits unrestricted use, distribution, and reproduction in any medium, provided the original work is properly cited.

The work described in this paper provides an evaluation of an aged pervious concrete pavement in the Northeastern United States to provide a better understanding of the long-lasting effects of placement techniques as well as the long-term field performance of porous pavement, specifically in areas susceptible to freezing and thawing. Multiple samples were taken from the existing pavement and were examined in terms of porosity and unit weight, compressive and splitting tensile strength, and the depth and degree of clogging. It was concluded that improper placement and curing led to uneven pavement thickness, irregular pore distribution within the pervious concrete, and highly variable strength values across the site, as well as sealed surfaces that prevented infiltration.

\section{Introduction}

The Stormwater Research and Demonstration Park at Villanova University (Greater Philadelphia area) is comprised of more than one dozen Stormwater Control Measures (SCMs), which are also known as Best Management Practices (BMPs). The pervious concrete site, which is the focus of this paper, is located between two dormitories in the middle of Villanova University campus. Originally, this site consisted of an asphalt paved area and a conventional storm sewer system which channeled runoff directly to the headwaters of Mill Creek, a high-priority stream on Pennsylvania's Clean Water Act (303d) list. The site serves primarily as a pedestrian walkway that occasionally experiences light maintenance vehicle and automobile traffic. In August 2002, the conventional materials were demolished and three infiltration beds (sized to accept approximately $5 \mathrm{~cm}$ of rainfall) were constructed with a pervious concrete surface. Originally, the entire pedestrian area was pervious; however, the surface failed and the site was reconstructed in May 2003 with a combination of traditional and pervious concrete [1]. In October 2004, several sections of the pervious concrete were again removed and repaired due to localized deterioration and cracking. Since that time, significant deterioration of the concrete has occurred.
Several Key Factors: environmental effects, material inconsistencies, and inadequate installation methods led to the deterioration of the original pervious concrete surface. Excessively high temperatures during installation resulted in inconsistent mixing and difficulties with finishing. Additionally, the curing process was improperly accelerated by the excessive heat, reducing strength and affecting aggregate bonding. The mixing time in the trucks varied with inconsistent travel times to the site. Workability of the concrete was low as there was a short window of time to finish the concrete surface. The finishing technique used was also inadequate. At least two different finishing methods were used, including a vibratory screed and modified plate tamper. Neither of the methods proved to be functional, however, and several areas were left in an unfinished state $[2,3]$.

In May 2003, the original pervious concrete surface, which covered the entire pedestrian area, was replaced. The pervious area was significantly decreased from the original pervious design. It was determined through site runoff data and visual observations of the first design during storm events that the pervious area could be decreased if it was strategically located to collect the same amount of runoff. A new layout (Figure 1) was designed which consisted of a pervious concrete perimeter (marked red) around three crowned standard concrete sections (marked purple) [1-3]. 


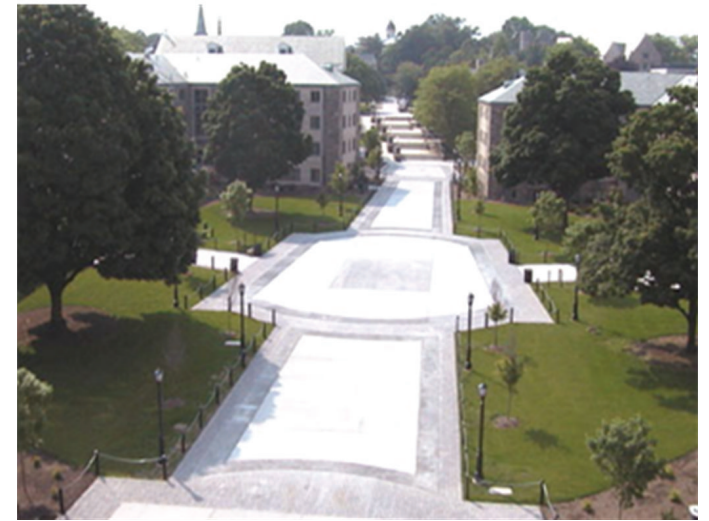

(a)

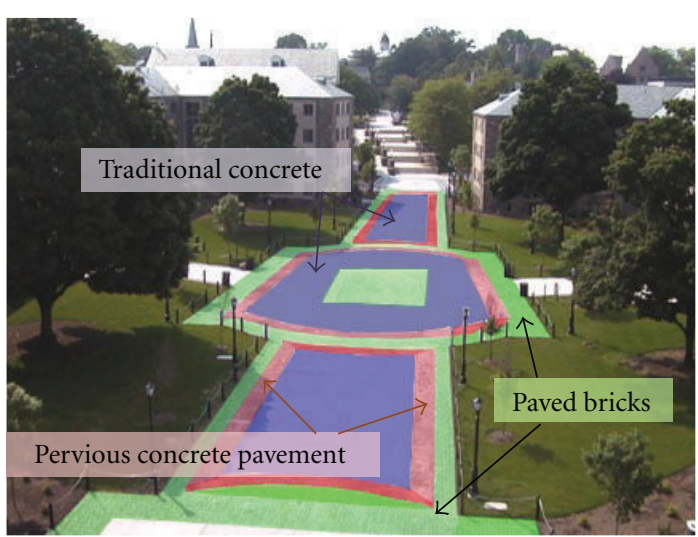

(b)

Figure 1: (a) Aerial view of Villanova Campus Pervious Concrete Site in 2003. (b) pervious concrete (red), traditional concrete (purple), and paved brick (green) surfaces identified.

In October 2004, approximately half of the sections of the pervious concrete area were showing signs of deterioration and these sections were removed and replaced with new pervious concrete (marked green "repaired" in Figure 2). Subsequent evaluation of the pavement condition in June 2006 revealed that some sections of the pavement were completely clogged (marked red "sealed" in Figure 2), while other sections experienced cracking (marked blue "cracked" in Figure 2). It should be mentioned here that the pervious concrete placed in 2003 and 2004 was a standard Florida Mix [4].

The construction process of the present system was intended to avoid the problems encountered during construction of the first surface. For example, the construction was completed during cooler months and the water was added at the site to create a more consistent and workable mix. On-site mixing allowed for better control of the mixing and curing process. A weighted drum was rolled over the concrete after it was placed for compaction and finishing. A modified version of this method is still used in practice today and includes a weighted vibratory hand roller $[2,3]$.

Despite the second placement and repairs, the pervious concrete surface installed in May 2003 and October 2004 has degraded significantly and is slated for demolition in 2012 . The impending removal of this concrete presented a unique opportunity to perform a forensic evaluation of one of the earliest pervious concrete installations in the northeastern portion of the United States.

The objectives of this research were to evaluate the following properties of pervious concrete:

(i) extent of clogging and the resulting decrease in infiltration capacity,

(ii) extent of phosphorous adsorption onto the concrete,

(iii) mechanical properties evaluation.

The results of this work are placed into the context of the current state of understanding of pervious concrete properties. This can provide researchers and practitioners with insights into mechanisms of failure as well as an understanding of the ability of pervious concrete to adsorb phosphorous in the long term. A thorough examination of failures, as well as successes, is required to enable the widespread acceptance of this material.

\section{Literature Review}

Pervious surfaces are attractive alternatives to traditional concrete pavements because of their role in stormwater management and mitigating Urban Heat Island (UHI) effects $[5,6]$. The concrete industry's understanding of pervious concrete is evolving with the ongoing research of the materials mechanical and chemical properties [7]. The existing literature on the properties of pervious concrete, both mechanical and hydrological, are examined in this section to provide a better understanding of the behavior of pervious pavements.

2.1. Mechanical Properties. Adequate strength of pervious concrete is critical to ensuring that it provides a long-term, durable solution to storm water management. There is a tradeoff between strength and porosity (related to permeability), and it is typically up to the designer to determine which parameter controls the design [8]. Pervious concrete can develop compressive strengths upwards of $28 \mathrm{MPa}$, with typical values around $17 \mathrm{MPa}$. As with traditional concrete, the properties and combinations of ingredient materials, as well as batching, placement techniques, and environmental conditions, contribute to the actual in-place strength [9]. Destructive testing of drilled cores is the best measure of in-place strengths, as compaction differences make cast cylinders less representative of field concrete. Flexural strength in pervious concrete generally ranges between about $1 \mathrm{MPa}$ and 3.8 MPa. Many factors influence the flexural strength, particularly degree of compaction, porosity, and the aggregate-to-cement $(\mathrm{A} / \mathrm{C})$ ratio. However, for typical applications utilizing pervious concrete, measurement of flexural strength is not required [10]. 


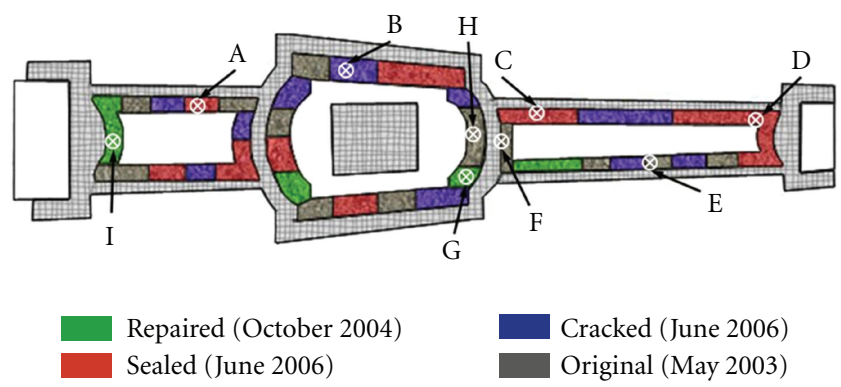

Figure 2: April 2011 core sample locations and delineation of physical conditions of concrete. Note: during the April 2011 inspection, all pervious concrete areas were found to be completely sealed.

Drying shrinkage develops earlier in pervious concrete, but is significantly less than conventional concrete [11]. Specific values vary with different mixtures and materials used, but typically the values are approximately half of that expected for conventional concrete mixtures. The material's low paste and mortar content is a possible explanation. Approximately $50 \%$ to $80 \%$ of shrinkage occurs within the first 10 days, compared to $20 \%$ to $30 \%$ in the same period for conventional concrete. Often pervious concrete is made without control joints and allowed to crack randomly [10].

Aggressive chemicals in soils or water, such as acids and sulfates, are a concern to conventional concrete and pervious concrete alike, and the mechanisms for chemical attack are similar. However, the open structure of pervious concrete may make it more susceptible to attack over a larger area. Pervious concrete can be used in areas of high-sulfate soils and ground water if isolated from direct contact. Placing the pervious concrete over a $150 \mathrm{~mm}$ layer of $25 \mathrm{~mm}$ maximum top size aggregate provides a pavement base, storm water storage, and isolation for the pervious concrete. Unless these precautions are taken in aggressive environments, recommendations from ACI 201 on waterto-cement ratio and material types/proportions should be followed [10]. Similarly, care should be taken to minimize the degradation caused by deicing materials by minimizing their use soon after placement [12].

The rougher surface texture and open structure of pervious concrete can lead to the raveling of aggregate particles when the pavements are plowed during snow events. This abrasion and raveling is one of the major reasons why applications such as road ways are generally not suitable for pervious concrete in seasonal climates with harsh winters. However, the open structure does prevent refreezing of melted snow, which decreases the amount of deicing materials required to clear the pavement. Most pervious concrete pavements will have a few loose aggregates on the surface in the early weeks after opening to traffic. These rocks were typically loosely bound to the surface initially and popped out because of traffic loading. After the first few weeks, the rate of surface raveling is usually reduced considerably and the pavement surface becomes much more stable [13]. Proper compaction and curing techniques reduce the occurrence of surface raveling.
2.2. Hydrological and Chemical Properties. Pervious pavements allow stormwater to infiltrate into the ground as a method to meet both volume and pollutant reduction goals $[1,14,15]$. Typical values for the infiltration rate of pervious concrete vary between $0.20 \mathrm{~cm} / \mathrm{s}$ and $0.54 \mathrm{~cm} / \mathrm{s}$, although values in excess of $1.2 \mathrm{~cm} / \mathrm{s}$ have been measured in the laboratory $[10,16]$. The porosity of pervious concrete usually varies between $15 \%$ and $25 \%$ [10]. It is necessary for pervious pavements to retain their porosity and high infiltration rates to continue to meet the storm water control goals for which they were designed. In addition to the total porosity, the interconnectivity of the pores plays an important role as it is directly related to the infiltration rate [17]. Recently developed computer models allow virtual characterization of pervious concrete microstructure [18].

The large pore sizes, which allow for increased infiltration, can also allow smaller sediment particles to accumulate within these spaces. Clogging of the pores can greatly limit the performance of these systems from a hydrological perspective. Proper installation and routine maintenance are required to minimize clogging. Vacuum street sweeping, pressure washing, or a combination of the two are the most commonly used methods to dislodge materials clogging the pores of pervious pavements [19-21].

Pervious concrete improves the quality of water in three ways. The first way is that the pervious concrete is used in conjunction with an infiltration or retention bed to prevent polluted water from travelling downstream. The second way is that pollutants within the storm water runoff are adsorbed onto the pavement particles as the water is infiltrated through the system. The third way is that the pavement traps sediments, to which pollutants (nutrients and metals) adsorb, in the pore spaces [10, 22-26].

\section{Evaluation of the Properties of the Pervious Concrete Site}

The properties of the pervious concrete investigated in this study have been evaluated at several points in time. When the concrete was placed in May 2003, two cylinder samples were cast to determine the concrete's compressive strength. In June 2006, a thorough inspection of the site was performed to 


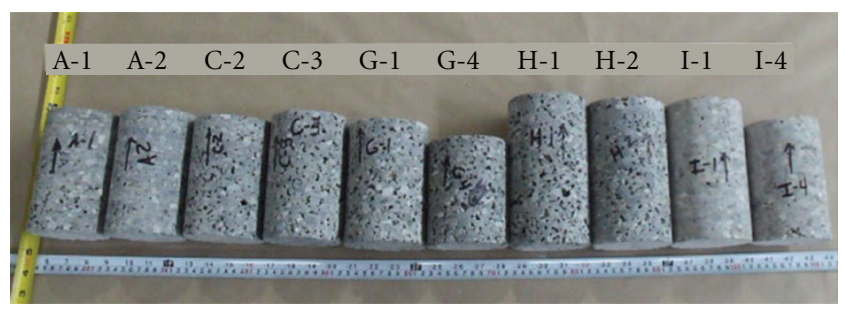

FIGURE 3: Concrete core samples used for compressive strength evaluation. Note that the length differences are due to uneven pavement thickness.

determine the extent of deterioration of the concrete as well as its infiltration capabilities (Figure 2). In April 2011, a total of 28 core samples were taken from nine different locations throughout the site. Each location was assigned a letter and number starting with location " $\mathrm{A}$ " and ending with location "I".

The following properties were evaluated for the 28 cores obtained in 2011: compressive and splitting tensile strength, unit weight, porosity (using both image analysis and volumetric method), infiltration testing, and phosphorous adsorption to both the concrete and the sediments found within the pores. The methods used and the results obtained are discussed for each property evaluated.

3.1. Compressive and Splitting Tensile Strength and Unit Weight. Of the 28 core samples taken from the Pervious Concrete Site on Villanova's campus, 10 were used for strength and unit weight evaluation (Figure 3 ). The top and bottom of each sample was saw-cut to create smooth surfaces. The core samples were measured and weighed prior to testing. The diameter of both the top and bottom as well as the length of each core sample was measured in three different locations and the average for each cylinder was reported (Table 1). The measured unit weights, with an average of $134 \mathrm{pcf}\left(2147 \mathrm{~kg} / \mathrm{m}^{3}\right)$, are greater than the values typically expected for pervious concrete. Typically, the in-place density of pervious concrete is between $100 \mathrm{pcf}$ $\left(1602 \mathrm{~kg} / \mathrm{m}^{3}\right)$ and $125 \mathrm{pcf}\left(2002 \mathrm{~kg} / \mathrm{m}^{3}\right)$ [10]. These higher than expected unit weights indicate that some sections of pervious concrete were "overworked" during installation, resulting in significant reduction of porosity.

Compressive strength tests were performed following ASTM C39-05 [27]. Samples were capped with neoprene pads and loaded at a continuous rate at $1.78 \mathrm{kN} / \mathrm{s}$ to $2.22 \mathrm{kN} / \mathrm{s}$ until failure. Correction factors were applied to the strength results as per ASTM C42-04 [28], as the cores had a lengthto-diameter ratio $(\mathrm{L} / \mathrm{D})$ less than 1.75 . The compressive strength was measured between 15.6 and $43.0 \mathrm{MPa}$, as presented in Figure 4. Despite the fact that the design strength for pervious surfaces was achieved, significant variation in strength across the sample locations was observed. This variability indicates that there were inconsistencies in the placement and curing of the pervious concrete as well as in the intrinsic material properties of the concrete.

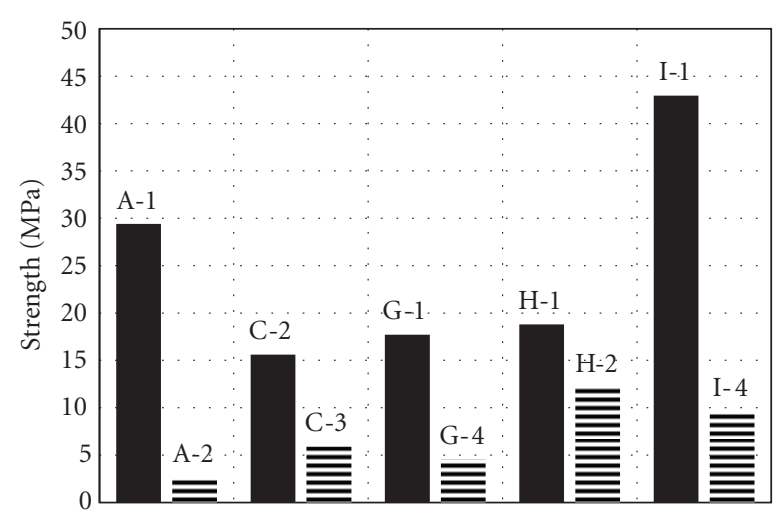

Compressive strength
= Tensile strength

FIGURE 4: Compressive and splitting tensile strength results for individual cores.

The splitting tensile strength was evaluated as per ASTM C496-04 [29]. Thin balsa wood bearing strips were used to distribute the load applied along the cylinder length. The samples were loaded continuously at a rate of $0.7 \mathrm{MPa} / \mathrm{min}$ to $1.4 \mathrm{kPa} / \mathrm{min}$ until failure. The maximum load sustained by the specimen was divided by appropriate geometrical factors to determine splitting tensile strength. The results of splitting tensile strength (Figure 4) show significant variability, as observed in case of compressive strength results.

As previously mentioned, two cylindrical samples of the pervious concrete were cast in May 2003, during site installation. Despite the low reliability and consistency associated with the sample casting of pervious concrete [10], the results of these tests can be used for comparison with compressive strength results obtained from the 2011 cores. The samples obtained in 2003 were placed in $10 \mathrm{~cm}$ diameter concrete cylinder molds and cured in a moist room for 28 days. The measured compressive strengths for the two samples were 23.9 and $23.5 \mathrm{MPa}$. These results compare favorably to the compressive strengths obtained for the samples cored in 2011 (Figure 4). The higher strength of laboratory prepared samples can be explained by the extended moist curing period. It is also important to note that the compressive strength for the 2011 samples represents the value for intact cores and therefore is not representative of the locations where the pavement has completely deteriorated.

3.2. Porosity. Pervious pavement is generally designed to contain approximately $15 \%$ to $25 \%$ voids. The void space or porosity of a pervious pavement is directly related to the rate of infiltration, and thus its effectiveness as a storm water management system [30]. Since its initial construction in 2002, care has been taken at the pervious concrete site to minimize clogging. During construction in 2002, 2003, and 2004, all surrounding vegetated areas were stabilized to ensure that sediment was not carried onto the pervious pavements during storm events. The site was swept with 
TABle 1: Pervious concrete cores sample data.

\begin{tabular}{lcccc}
\hline Specimen & \multicolumn{2}{c}{ Average diameter $(\mathrm{cm})$} & Average length $(\mathrm{cm})$ & Unit weight $\left(\mathrm{kg} / \mathrm{m}^{3}\right)$ \\
\hline A-1 & Top & Bottom & 9.50 & 2195 \\
C-2 & 9.50 & 9.50 & 14.17 & 2082 \\
G-1 & 9.50 & 9.50 & 13.91 & 2114 \\
H-1 & 9.52 & 9.50 & 17.20 & 2066 \\
I-1 & 9.52 & 9.50 & 16.46 & 2243 \\
A-2 & 9.52 & 9.52 & 14.86 & 2210 \\
C-3 & 9.50 & 9.52 & 14.76 & 2082 \\
G-4 & 9.50 & 9.50 & 12.01 & 2098 \\
H-2 & 9.52 & 9.52 & 16.51 & 2130 \\
I-4 & 9.50 & 9.50 & 14.07 & 2275 \\
\hline Average & 9.50 & 9.50 & $\mathbf{1 4 . 8 6}$ & $\mathbf{2 1 4 5}$ \\
\hline STDEV & $\mathbf{9 . 5 0}$ & $\mathbf{9 . 5 0}$ & $\mathbf{1 . 5 2}$ \\
\hline
\end{tabular}

a vacuum street sweeper quarterly to remove any sediment trapped in the pore spaces. Despite these efforts, the pervious concrete exhibited visible clogging due to raveling, possibly caused by inadequate placing and finishing. A thorough inspection of the site performed in June 2006 revealed that approximately one-half of the pavement area was unable to infiltrate water (Figure 2). Although great care was taken to minimize clogging from sediments, the concrete was subjected to intense application of de-icing materials within several months of installation. The site under investigation is a major pedestrian thoroughfare in the university and, as such, was regularly treated with calcium chloride to prevent injuries.

The porosity of the pervious concrete specimens obtained in 2011 was examined to provide insight into the clogging that had occurred. Digital image analysis was used to determine clogging as a function of depth [31] using two-dimensional images [32]. Nine core samples were cut into $3.8 \mathrm{~cm}$ thick slices using a wet saw to achieve a clean, level surface at either end of the sample (Figure 5(a)). As such, six faces were created for a single core. In some cases, localized changes in pavement depth resulted in only four representative faces (samples D1, D2, E3) that were subject to further analysis. It should be noted that the top surfaces of the cores were not included in the image analysis due to significant surface damage and corresponding loose aggregate particles. Additionally, the coring and cutting process involved a wet saw that might have altered the existing pore structure.

After the samples were prepared, a digital image was taken of each face (Figure 5(b)). Once the image was obtained, it was processed using Adobe Photoshop software. All large pores visible in the image were manually filled with black color to distinguish between dark aggregate particles and pores (Figure $5(\mathrm{c})$ ). The image was converted into a binary image (Figure 5(d)), and the area occupied by the pores was calculated as a percentage of the total sample crosssectional area.

Additionally, the volumetric method was used to measure the total volume of pores in each of the analyzed samples. Each sample was measured to determine the total volume $(V)$. The dry mass of the sample was recorded $\left(m_{\text {dry }}\right)$. Next, samples were submerged in water and the buoyant mass was measured $\left(m_{b}\right)$. Knowing the density of water $\left(\rho_{w}\right)$, the porosity $(\phi)$ was determined using the following equation:

$$
\phi=\left[1-\frac{m_{\mathrm{dry}}-m_{w}}{\rho_{w} \times V}\right] \times 100 \% .
$$

The porosity versus core depth for nine separate locations, as obtained using image analysis, are summarized in Figure 6. Significant variations in the porosity exist between different locations and core depths. The values of porosity recorded were between $1 \%$ and $26 \%$, with only $19 \%$ of results larger than $15 \%$ (typically the lower threshold expected for pervious pavements). Porosity in the upper part of the pavement was consistently lower than that of the deeper sections of the pervious concrete. The extremely low porosity values observed in the top section indicate that at the time of evaluation, the pervious surface had lost its infiltration capacity. This loss of porosity is confirmed by visual inspection of the core A-3 presented in Figure 5(a). Additionally, sediment clogging of the void space of the pervious concrete system resembled hardened concrete paste rather than loose sediment, which would indicate that freezing and thawing contributed to concrete spalling, and loose pieces clogged the pores. Based on visual observations of the samples from locations D and I, these sections exhibited reduced void content due to excessive compaction during placement rather than passive clogging.

The summary of the porosity values obtained using the volumetric method is shown in Figure 7. Only 12\% of the samples tested had porosity greater than $15 \%$. Similar to the image analysis results, a trend of increasing porosity with depth was also observed.

3.3. Infiltration. Field infiltration tests were performed on the pervious concrete within $10 \mathrm{~cm}$ of where the cores were obtained. For this test, water was placed into a $10 \mathrm{~cm}$ 


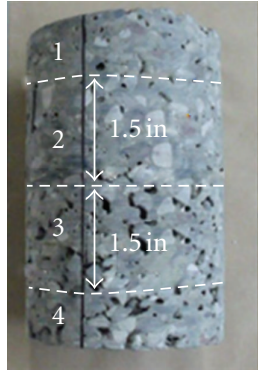

(a)

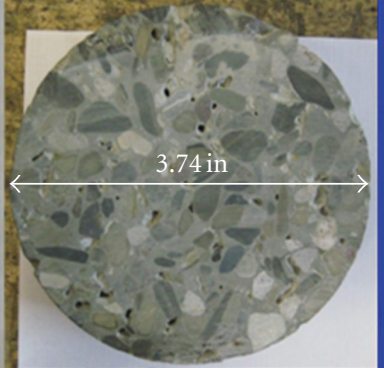

(b)

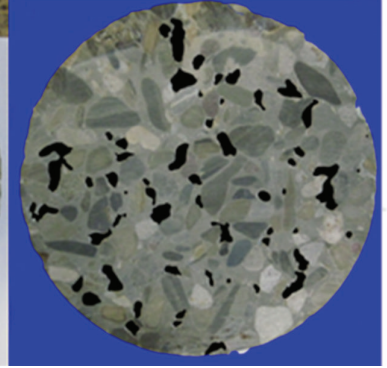

(c)

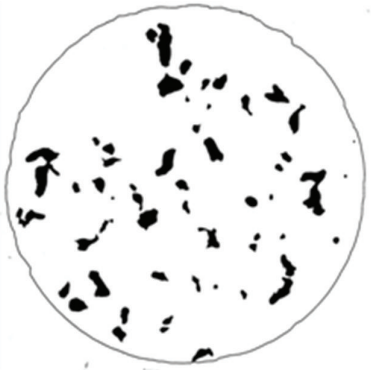

(d)

FIGURE 5: Image analysis of pervious core A-3 (porosity $=7.4 \%$ ).

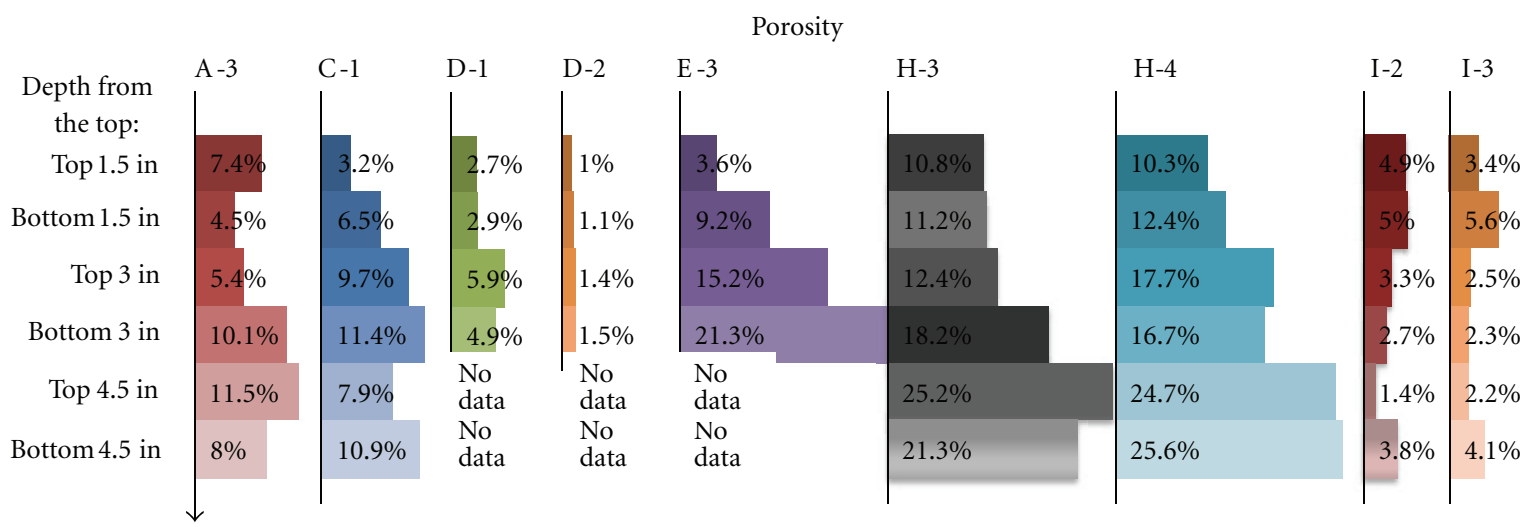

FIGURE 6: Porosity of nine concrete samples with respect to core depth evaluated using image analysis of sliced cores.

diameter concrete cylinder mold with a $22 \mathrm{~mm}$ hole drilled in the bottom and the length of time it took for the water to drain was recorded $[33,34]$. This cylinder has a gasket around the bottom to ensure that side leakage does not occur and that the water is forced into the pavement. The time, $t$ (seconds), was then used to calculate the infiltration rate, $k$ (in/hr), using the following equation $[35,36]$ :

$$
k=2533 e^{(-0.062 * t)} .
$$

This method was used to determine the infiltration rate as it was the same method used to evaluate the infiltration rate in 2006. It is important to note that ASTM C1701-09 is a more rigorous method to determine the infiltration rate of pervious concrete [37].

All of the field tests, with the exception of one, revealed that the top surface was sealed with no infiltration. The only location that exhibited any infiltration $(0.0003 \mathrm{~cm} / \mathrm{s})$ was near where sample series $F$ was obtained. These results are consistent with the porosity values measured (Figure 6) and indicate that clogging of the site, which was approximately $50 \%$ in 2006, was complete by 2011.

3.4. Phosphorous Adsorption. The pervious concrete site had been extensively monitored hydrologically as well as for water quality. Metals were detected in the pore water of the natural soils underlying the infiltration bed and in the water stored in the infiltration bed. The source of the copper was the downspouts and gutters from the roof runoff, which were directly piped into the infiltration beds; thus, this water did not infiltrate through the pavements. Once the pervious concrete storm water control measure was constructed, the university ceased using fertilizers near the site; therefore, one would expect the concentration of phosphorous adsorbed onto the sediments and to the concrete to be fairly low $[1,22]$.

To evaluate this hypothesis, the amount of phosphorus adsorbed to the sediments contained within the pores of the pervious concrete and the concrete cores was determined. Twenty specimens, four from each location $A, C, G, H$, and $\mathrm{I}$, were analyzed. To determine the concentration of phosphorous adsorbed to the sediments within the pores, the samples were placed in shaker for one hour to dislodge the sediments. The samples were then removed from the shaker and placed on a flat surface until the sediment settled to the bottom. The extract solution was then removed from the sample and was filtered through a $0.45 \mu \mathrm{m}$ filter. The filtered extract was then analyzed for phosphorous concentration using a Systea Scientific EasyChem machine [38]. The measured concentrations were averaged for each location and related to the mass of the sediment and the mass of the concrete to place the results into context (Figure 8).

As expected, the phosphorous concentrations were low for both the sediment and the concrete. In addition, the 


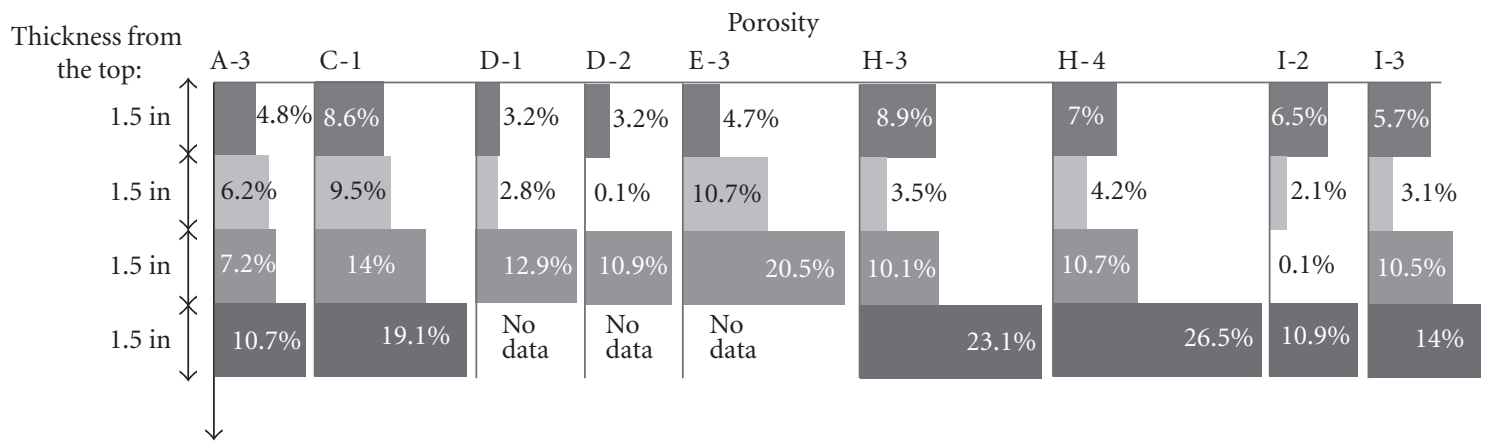

Figure 7: Porosity of nine concrete samples with respect to core depth determined by volumetric method.

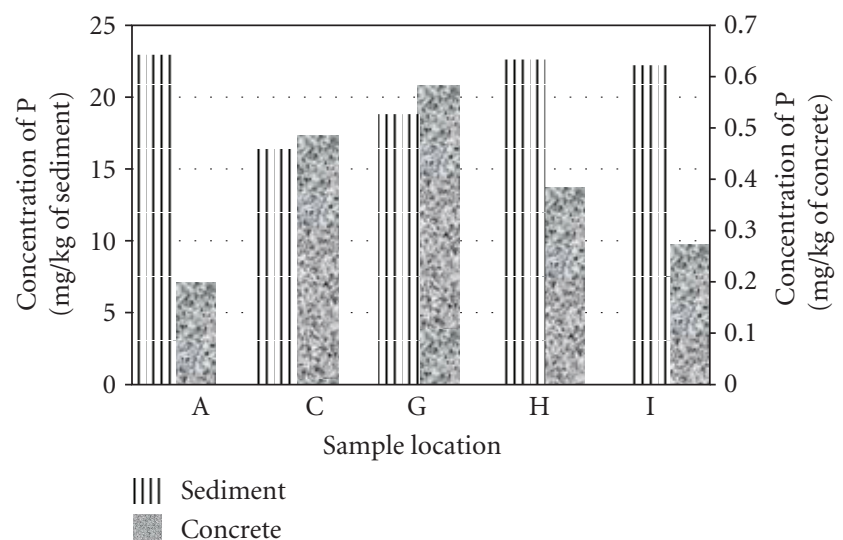

FIGURE 8: Concentration of phosphorus adsorbed to sediments within pores (primary $\mathbf{y}$-axis) and to the concrete (secondary $\mathbf{y}$ axis).

concentrations on the sediment were much higher than those for the concrete, due to the surface area of smaller particles being greater than that of larger particles. Water quality monitoring revealed that the pervious concrete infiltration SCM removed $94.3 \%$ of phosphorous [22]. The inflow concentrations were typically around $1 \mathrm{mg} / \mathrm{L}$ [39]. When the sample locations are compared to the site inspection that was performed in 2006 (Figure 2), some trends emerge. The phosphorous concentration of the sediment is the lowest for sample C, which is from an area identified as sealed in 2006. The other samples, A, G, H, and I, received more runoff, and thus more phosphorous, than sample C. Sample A was obtained from the border of two areas identified as sealed and cracked, and this area probably received the runoff from the sealed section as well as from the conventional concrete. Samples G and H were taken from an area of the 2003 concrete pour, while sample I was taken from an area of the 2004 pour.

\section{Summary and Conclusions}

The pervious concrete site at Villanova University was analyzed in terms of performance and durability after eight years of use. The strength of the concrete proved to be adequate for its intended use; however, significant variabilities in the measured porosity, unit weight, and strength values indicate inconsistencies in construction practices and material properties. Several factors that contributed to the decreased effectiveness of the pervious concrete were identified. Improper construction methods altered the desired pore distribution and significantly reduced the permeability of the sections, gradually leading to impervious surfaces. The reduced permeability decreased the effectiveness of the site to collect storm water, which further lead to reduced capacity to adsorb phosphorous. While the pervious surface allowed water ingress of $50 \%$ of its capacity in 2006, it became completely sealed by 2011. Additionally, raveling from freezethaw cycles played a key role in the eventual ineffectiveness of the concrete to allow infiltration into the ground, as verified by the inspection of particles locked in concrete pores. The varying porosity across the depth of the pavement was the result of improper installation procedures.

Although the design and installation practices of pervious concrete have improved tremendously over the past eight years, great care must be taken during installation to ensure that the concrete is properly placed, finished, and cured. This involves adequate training procedures in the finishing of the pervious surface. New methods that involve single-pass weighted rollers reduce the consolidation of aggregates near the surface and allow for better pore distribution. Proper mix design for the intended use of the pervious concrete with attention to freeze-thaw characteristics is also critical to the long-term durability and performance of porous concrete.

\section{Acknowledgments}

The authors gratefully acknowledge support received from Villanova University. This work was conducted in the Structural Engineering Teaching and Research Laboratory (SETRL), the Soils Laboratory, and the Water Resources Teaching and Research Laboratory at Villanova University; as such, the authors acknowledge the support that has made these laboratories and its operation possible. The authors would also like to thank Jennifer Gilbert Jenkins for her help with the phosphorous testing. 


\section{References}

[1] M. Kwiatkowski, A. L. Welker, R. G. Traver, M. Vanacore, and T. Ladd, "Evaluation of an infiltration best management practice utilizing pervious concrete," Journal of the American Water Resources Association, vol. 43, no. 5, pp. 1208-1222, 2007.

[2] R. G. Traver, A. L. Welker, M. Horst, M. Vanacore, A. Braga, and L. Kob, "Lessons in porous concrete," Stormwater, pp. 130-136, 2005.

[3] R. G. Traver, A. L. Welker, C. Emerson, M. Kwiatkowski, T. Ladd, and L. Kob, "Villanova urban stormwater partnership: porous concrete," Stormwater, pp. 30-45, 2004.

[4] Florida Concrete and Products Association, Recommended Specifications for Pervious Pavement, publication 650.

[5] L. Frazer, "Paving paradise: the peril of impervious surfaces," Environmental Health Perspectives, vol. 113, no. 7, pp. A456A462, 2005.

[6] N. Delatte and S. S. Schwartz, "Sustainability benefits of pervious concrete pavement," in Proceedings of the 2nd International Conference on Sustainable Construction Materials and Technologies, Universita Politecnicadelle Marche, Ancona, Italy, 2010.

[7] J. Kevern, K. Wang, M. T. Suleiman, and V. R. Schaefer, "Pervious concrete construction: methods and quality control," NRMCA Concrete Technology Forum: Focus on Pervious Concrete, Nashville, Tenn, USA, May 2006.

[8] N. Delatte, M. Miller, and A. Mrkajic, Portland Cement Pervious Concrete Pavement: Field Performance Investigation on Parking Lot and Roadway Pavements, Cleveland State University, Cleveland, Ohio, USA, 2007.

[9] M. Offenberg, "Producing pervious pavements," Concrete International, vol. 27, no. 3, pp. 50-54, 2005.

[10] P. Tennis, M. Leming, and D. Akers, Pervious Concrete Pavements, Portland Cement Association, Skokie, Ill, USA, National Ready Mixed Concrete Association, Silver Spring, Md, USA, 2004.

[11] V. M. Malhotra, "No-fines concrete-its properties and applications," Journal of American Concrete Institute, vol. 73, no. 11, pp. 628-644, 1976.

[12] K. Wang, D. E. Nelsen, and W. A. Nixon, "Damaging effects of deicing chemicals on concrete materials," Cement and Concrete Composites, vol. 28, no. 2, pp. 173-188, 2006.

[13] J. T. Kevern, K. Wang, and V. R. Schaefer, The Effect of Coarse Aggregate on the Freeze-Thaw Durability of Pervious Concrete, Portland Cement Association, 2008.

[14] Stormwater Technology Fact Sheet, Porous Pavement Publication. EPA 832-F-99-023, US Environmental Protection Agency, Office of Water, Washington, DC, USA, 1999.

[15] C. Dierks, P. Gobel, and W. Benze, "Next generation water sensitive stormwater management techniques," in Proceedings of the 2nd National Conference on Water Sensitive Urban Design, Brisbane, Australia, 2002.

[16] M. Legret, V. Colandini, and C. LeMarc, "Effects of porous pavement with reservoir structure on the quality of runoff water and soil," Science of the Total Environment, vol. 190, special issue, pp. 335-340, 1996.

[17] M. S. Sumanasooriya and N. Neithalath, "Pore structure features of pervious concretes proportioned for desired porosities and their performance prediction," Cement and Concrete Composites, vol. 33, no. 8, pp. 778-787, 2011.

[18] D. R. Bentz, "Virtual pervious concrete: microstructure, percolation, and permeability," ACI Materials Journal, vol. 105, no. 3, pp. 297-301, 2008.
[19] L. M. Haselbach, S. Valavala, and F. Montes, "Permeability predictions for sand-clogged Portland cement pervious concrete pavement systems," Journal of Environmental Management, vol. 81, no. 1, pp. 42-49, 2006.

[20] L. M. Haselbach, "Potential for clay clogging of pervious concrete under extreme conditions," Journal of Hydrologic Engineering, vol. 15, no. 1, pp. 67-69, 2010.

[21] M. Chopra, S. Kakuturu, C. Ballock, J. Spence, and M. Wanielista, "Effect of rejuvenation methods on the infiltration rates of pervious concrete pavements," Journal of Hydrologic Engineering, vol. 15, no. 6, Article ID 009006QHE, pp. 426433, 2010.

[22] M. Horst, A. Welker, and R. Traver, "Multiyear performance of a pervious concrete infiltration basin BMP," Journal of Irrigation and Drainage, vol. 137, no. 6, pp. 352-358, 2011.

[23] K. F. Bruce, Porous Pavements, Taylor and Francis, Boca Raton, Fla, USA, 2005.

[24] Z. Teng and J. J. Sansalone, "In-situ storm water treatment and recharge through infiltration: particle transport and separation mechanisms," Journal for Environmental Engineering, vol. 130, no. 9, pp. 1008-1020, 2004.

[25] M. Scholz and P. Grabowiecki, "Review of permeable pavement systems," Building and Environment, vol. 42, no. 11, pp. 3830-3836, 2007.

[26] B. T. Rushton, "Low-impact parking lot design reduces runoff and pollutant loads," Journal of Water Resources Planning and Management, vol. 127, no. 3, pp. 172-179, 2001.

[27] ASTM Standard C39-05, Standard Test Method for Compressive Strength of Cylindrical Concrete Specimens, vol. 4 of Annual Book of ASTM Standards, ASTM International, West Conshohocken, Pa, USA, 2nd edition.

[28] ASTM Standard C42-04, Standard Test Method for Obtaining and Testing Drilled Cores and Sawed Beams of Concrete, vol. 4 of Annual Book of ASTM Standards, ASTM International, West Conshohocken, Pa, USA, 2nd edition.

[29] ASTM Standard C496-04, Standard Test Method for Splitting Tensile Strength of Cylindrical Concrete Specimens, vol. 4 of Annual Book of ASTM Standards, ASTM International, West Conshohocken $\mathrm{Pa}$, 2nd edition.

[30] D. Akers, M. Leming, and P. Tennis, Pervious Concrete Pavements, Portland Cement Association, Skokie, Ill, USA, National Ready Mixed Concrete Association, Silver Spring, Md, USA, 2004.

[31] E. Masad, B. Muhunthan, N. Shashidhar, and T. Harman, "Internal structure characterization of asphalt concrete using image analysis," Journal of Computing in Civil Engineering, vol. 13, no. 2, pp. 88-95, 1999.

[32] M. S. Sumanasooriya, D. P. Bentz, and N. Neithalath, "Predicting the permeability of pervious concretes from planar images," NRMCA 2009 Concrete Technology Forum: Focus on Performance Prediction, pp. 11, 2009.

[33] N. Delatte, D. Miller, and A. Mrkajic, "Portland cement pervious concrete pavement: field performance investigation on parking lot and roadway pavements," RMC Research and Education Foundation, Cleveland State University, Cleveland, Ohio, USA, http://rmc-foundation.org/images/Long\%20Term \%20Field\%20Performance\%20of\%20Pervious\%20Final\%20 Report.pdf.

[34] P. Jeffers, Water quality comparison of pervious concrete and porous asphalt products for infiltration best management practices, M.S. thesis, Villanova University, 2009, http:// www3.villanova.edu/vusp/Outreach/theses.htm.

[35] D. Miller, Field performance of PCPC in severe freeze-thaw environments, M.S. thesis, Cleveland State University, 2007. 
[36] A. Mrkajic, Investigation and evaluation of PCPC using nondestructive testing and laboratory evaluation of field samples, M.S. thesis, Cleveland State University, 2007.

[37] ASTM Standard C1701-09, Standard Test Method for Infiltration Rate of In Place Pervious Concrete, vol. 4 of Annual Book of ASTM Standards, ASTM International, West Conshohocken, $\mathrm{Pa}, \mathrm{USA}, 2 \mathrm{nd}$ edition.

[38] J. O'Dell, Method 365.1 Determination of Phosphorus by Semi-Automated Colorimetry, U.S. Environmental Protection Agency, 1993.

[39] M. Kwiatkowski, Water quality study of a porous concrete infiltration best management practice, M.S. thesis, Villanova University, 2004. 

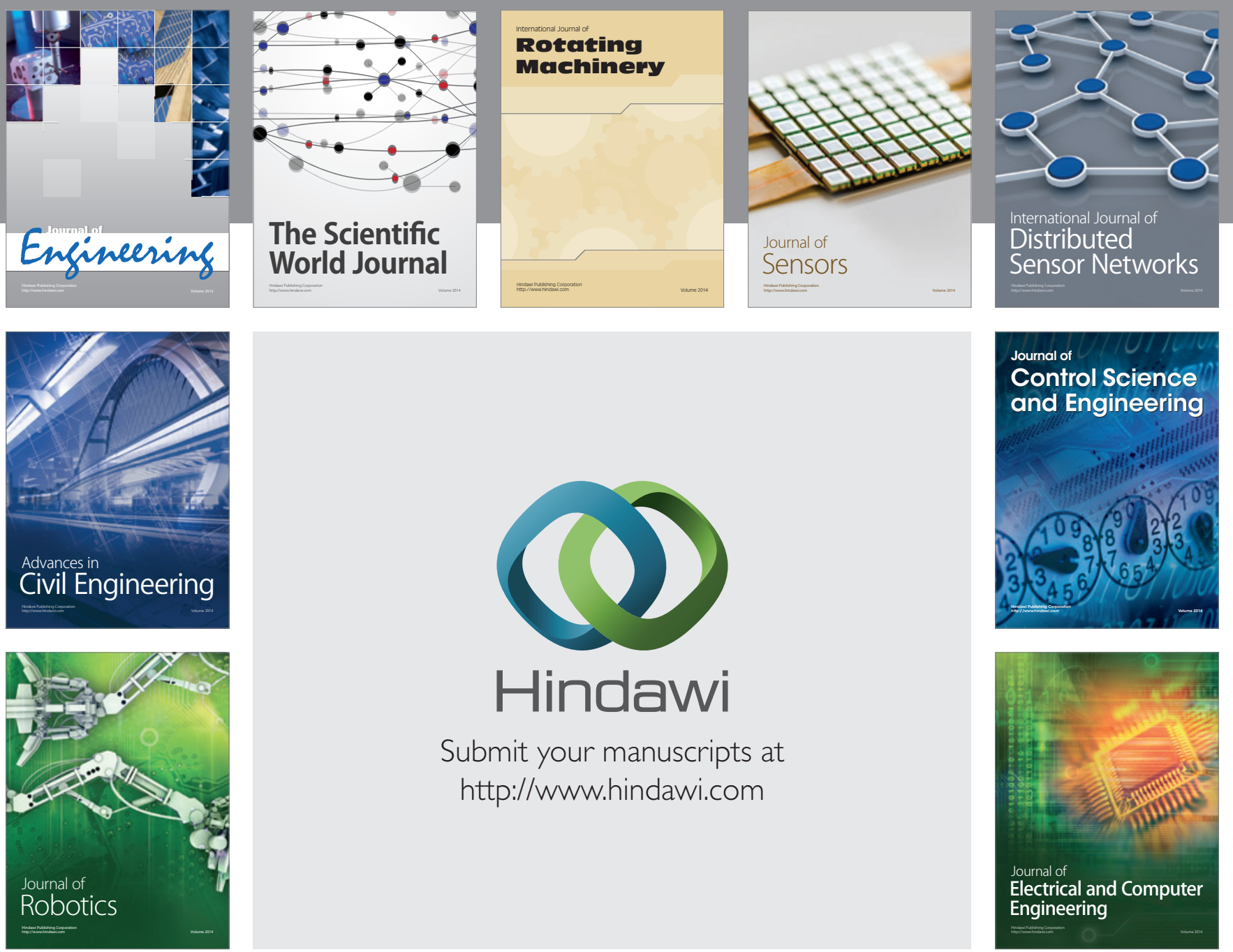

Submit your manuscripts at

http://www.hindawi.com
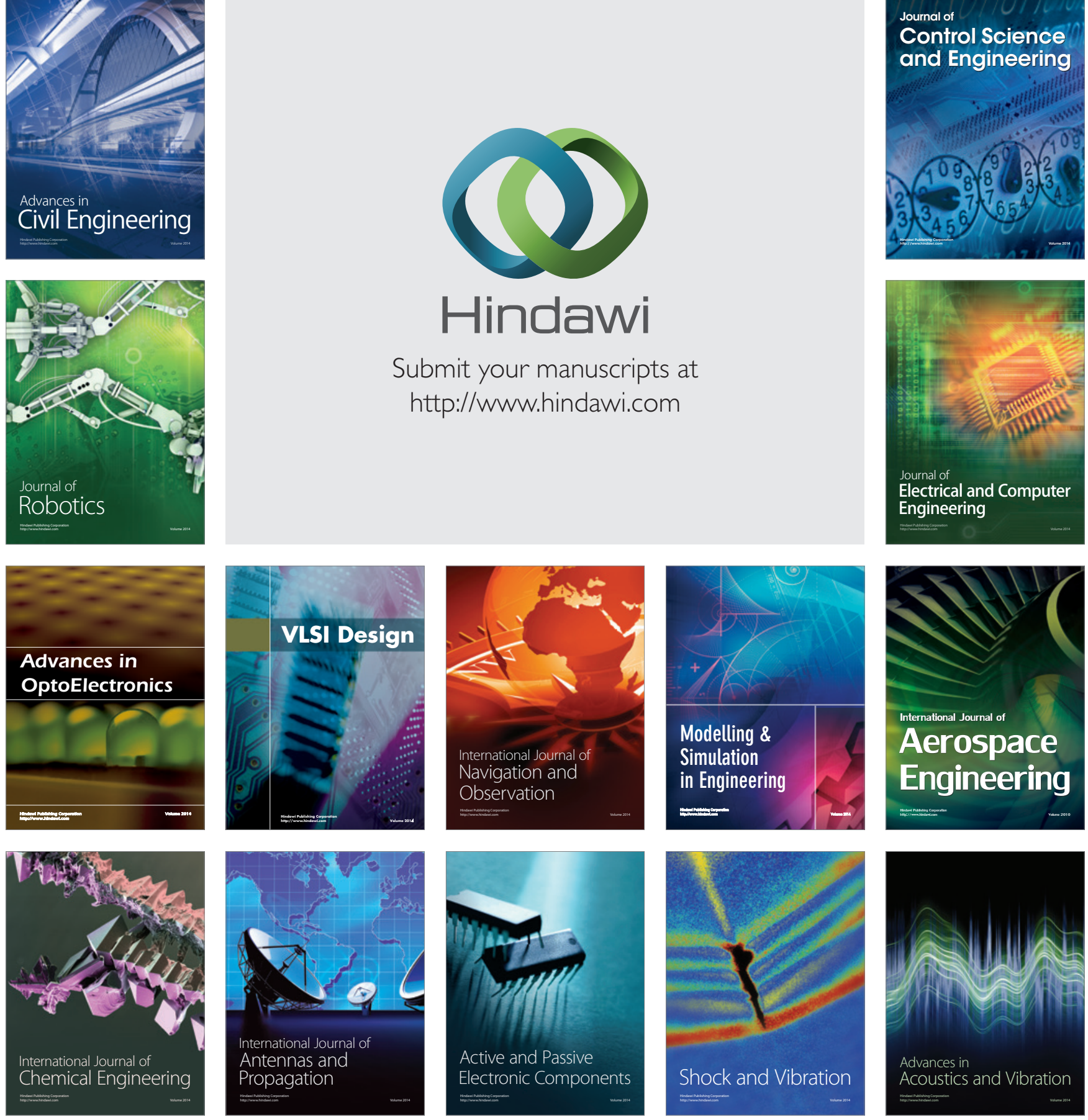